\title{
Can endoscopic papillary balloon dilation really preserve sphincter of Oddi function?
}

\author{
I Yasuda, E Tomita, M Enya, T Kato, H Moriwaki
}

\begin{abstract}
Background-Endoscopic papillary balloon dilation (EPBD) is assumed to preserve sphincter of Oddi function because it causes little trauma to the papilla. However, few studies have addressed this issue specifically. In this study, we investigated whether EPBD can preserve sphincter function, and evaluated whether or not such preservation has clinical significance.

Methods-Seventy patients with common bile duct (CBD) stones were randomly assigned to EPBD or endoscopic sphincterotomy (EST). Sphincter of Oddi (SO) function was measured by endoscopic manometry before, one week after, and one year after treatment. Incidence of pneumobilia and later complications were compared between the two groups at one year. Series manometric data were compared within each group and between the two groups. For a more detailed analysis of the cumulative incidence of later complications, retrospective cohorts were added to the study groups, giving a total number of 235 patients in the EPBD group and 126 in the EST group.
\end{abstract}

Results-Baseline characteristics did not differ significantly between the 35 EPBD and 35 EST patients. CBD stones were discharged successfully in all cases. CBD pressure, SO basal and peak pressures, and contraction frequency decreased significantly at one week in both groups. The damage was more severe in the EST group, and SO contraction completely disappeared in 23 patients in this group. The incidence of pneumobilia was significantly lower in the EPBD group than in the EST group $(p<0.01)$ whereas CBD stones recurred and cholecystitis appeared at a similar rate in both groups at one year. A complete series of manometric data up to one year was obtained in 55 patients; 28 in the post-EPBD and 27 in post-EST groups. In the post-EPBD group, SO basal and peak pressures significantly recovered at one year compared with data at one week but these measures still remained significantly lower than those before EPBD $(p<0.01)$. In the post-EST group, SO contraction did not recover even after one year. A Kaplan-Meier analysis of 235 EPBD and 126 EST patients for a median follow up of 37 months revealed significantly lower incidences of biliary complications such as recurrent $\mathrm{CBD}$ stones and cholangitis, and cholecystitis in the EPBD group than in the EST group $(p<0.05)$. The risk of pneumobilia was also significantly lower in the EPBD group $(\mathrm{p}<0.01)$.

Conclusions-Preservation of papillary function after EPBD was not complete but remained somewhat reduced. However, preservation was more successful with EPBD than with EST. Such preservation may be clinically beneficial for the prevention of later complications.

(Gut 2001;49:686-691)

Keywords: endoscopic papillary balloon dilation; endoscopic manometry; sphincter of Oddi; common bile duct stone

Endoscopic papillary balloon dilation (EPBD) has been reported as a potential alternative to endoscopic sphincterotomy (EST) for removing common bile duct (CBD) stones. ${ }^{1-9}$ EPBD is assumed to have some advantages over EST. For example, in EPBD, complications such as bleeding and perforation seldom occur because the bile duct orifice is extended by balloon inflation. EPBD is also expected to preserve sphincter of Oddi (SO) function. ${ }^{10}{ }^{11}$ However, in practice, we often experience that the CBD is easily cannulated in cases previously treated with EPBD. Such clinical findings suggest that preservation of papillary function may be incomplete after EPBD. In this study, we investigated whether or not EPBD can completely preserve SO function. Moreover, we studied whether or not such preservation is clinically beneficial.

\section{Patients and methods}

PATIENTS

The study was performed at the First Department of Internal Medicine, Gifu University and at the Department of Gastroenterology, Gifu Municipal Hospital. Candidate patients were those with possible CBD stones diagnosed by biliary symptoms and abnormality of biliary enzymes, or whose presence was suspected through other imaging tests. Patients were excluded from the study if they had acute pancreatitis (abdominal pain with hyperamylasaemia of more than twice the upper normal limit), severe cholangitis with disturbance of consciousness and shock state, coagulopathies, malignant diseases, or a history of previous EPBD or EST. If the patient met the criteria,

Abbreviations used in this paper: $\mathrm{EPBD}$, endoscopic papillary balloon dilation; CBD, common bile duct; EST, endoscopic sphincterotomy; SO, sphincter of Oddi; ERCP, endoscopic retrograde cholangiopancreatography. 
Table 1 Baseline characteristics of patients included in the manometric study

\begin{tabular}{llc}
\hline & $E P B D(n=35)$ & EST $(n=35)$ \\
\hline Age (y) & $69.5(42-86)$ & $69.4(43-88)$ \\
Sex (F/M) & $19 / 16$ & $14 / 21$ \\
No of stones & $3.7(1-16)$ & $3.3(1-16)$ \\
Diameter of largest stone (mm) & $12.4(4-24)$ & $12.3(5-24)$ \\
Diameter of CBD (mm) & $15.1(6-30)$ & $14.7(6-30)$ \\
Use of mechanical lithotriptor & $17^{\star}$ & $9^{\star}$ \\
Gall bladder in situ & 30 & 26 \\
Concomitant gall bladder stone & 23 & 21
\end{tabular}

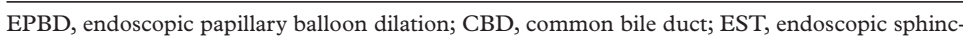
terotomy.

Values are mean (range) or number.

${ }^{\star} \mathrm{p}<0.05$.

Table 2 Comparison of post-EPBD and post-EST manometric data one week after treatment

\begin{tabular}{lcc}
\hline & Post-EPBD $(n=35)$ & Post-EST $(n=35)$ \\
\hline CBD pressure (mm Hg) & $2.0(0.4)^{\star \star}$ & $0.2(0.1)^{\star \star}$ \\
SO basal pressure (mm Hg) & $3.3(0.5)^{\star \star}$ & $0.6(0.3)^{\star \star}$ \\
SO peak pressure (mm Hg) & $58.3(5.5)^{\star \star}$ & $13.0(3.6)^{\star \star}$ \\
SO contraction frequency (per min) & $7.4(0.5)^{\star \star}$ & $2.5(0.7)^{\star \star}$
\end{tabular}

EPBD, endoscopic papillary balloon dilation; CBD, common bile duct; EST, endoscopic sphincterotomy; SO, sphincter of Oddi.

Values are mean (SEM).

${ }^{\star \star} \mathrm{p}<0.01$.

written informed consent was obtained before diagnostic endoscopic retrograde cholangiopancreatography (ERCP). If CBD stones were diagnosed by ERCP and selective deep cannulation to the CBD was successful without the use of antispastic drugs or precut of the papilla, endoscopic manometry was subsequently performed and patients were randomly assigned to EPBD or EST using blinded sealed envelopes prepared by random number generation. The envelopes were equally divided between the two study centres with block randomisation. Each institute's review board for human research approved the study protocol.

ENDOSCOPIC MANOMETRY

Patients underwent endoscopic manometry before, one week after, and one year after EPBD or EST. Diazepam (5-10 mg) was given intravenously at the start of ERCP, and endoscopic manometry was performed following diagnostic ERCP. A 4 French microtransducer catheter (Gaeltec Ltd, Scotland, UK) was inserted into the CBD through a biopsy channel of the fibrescope. CBD and SO pressures were determined from the waveforms obtained by the stationary pull through method. CBD and SO pressures were calibrated using basal duodenal pressure as the zero reference. Parameters measured were CBD pressure $(\mathrm{mm} \mathrm{Hg})$, SO basal pressure $(\mathrm{mm} \mathrm{Hg})$, SO peak pressure $(\mathrm{mm} \mathrm{Hg})$, and $\mathrm{SO}$ contraction frequency (per minute). At the end of the manometric analysis, scopolamine butylbromide $(20 \mathrm{mg}$ ) was given intravenously and therapeutic procedures were initiated.

\section{ENDOSCOPIC PAPILLARY BALLOON DILATION} (EPBD)

A balloon dilation catheter $(8 \mathrm{~mm}$ diameter; Maxforce, Boston Scientific Corporation, Massachusetts, USA) was inserted and inflated twice to a maximum diameter of $8 \mathrm{~mm}$; each inflation lasted for one minute at $6 \mathrm{~atm}$. After the balloon was deflated, the stones were extracted using a retrieval basket (Memory eight wire basket; Wilson-Cook Medical Inc., North Carolina, USA) and a retrieval balloon (Extracter XL; Boston Scientific Corporation, Massachusetts, USA). When the stone diameter was larger than $11 \mathrm{~mm}$, as shown by diagnostic ERCP, a mechanical lithotriptor (BML4Q; Olympus Corporation, Tokyo, Japan) was used to break the stones into fragments.

ENDOSCOPIC SPHINCTEROTOMY (EST)

EST was performed according to the standard method using a pull-type sphincterotome (KD-22Q; Olympus Corporation, Tokyo, Japan). The incision was made up to, but not beyond, the proximal hooding fold. In cases involving stones larger than $20 \mathrm{~mm}$, a mechanical lithotriptor was used.

All patients were hospitalised throughout the EPBD or EST treatment period. The radiation load was kept as low as possible during all procedures. No oral adjuvant chemolitholysis or contact dissolution agents were used before or after either procedure. CBD stones were discharged successfully in all EPBD and EST cases.

FOLLOW UP STUDY OF COMPLICATIONS

All patients were seen at the outpatient clinic at least one month, six months, and one year after discharge. At each visit, blood liver function tests and abdominal ultrasonography were performed. Abdominal radiograph, computed tomography, and other relevant examinations were requested when deemed necessary. If stone recurrence was suspected from symptoms, laboratory data, and/or images, ERCP was performed. In those cases in which recurrence was confirmed by ERCP, the prior treatment (EPBD or EST) was repeated and the recurrent stone was removed.

\section{OUTCOME MEASURES}

The primary end point was comparison of the manometric data between the post-EPBD and post-EST groups one year after treatment. Series manometric data were also evaluated within each group before, one week after, and one year after treatment. Secondary outcome measures were the incidence of pneumobilia and the incidence of later complications during one year of follow up. If recurrence was confirmed by ERCP during follow up, a final manometric study was avoided and additional treatment was performed.

\section{STATISTICAL ANALYSIS}

Series manometric data before and after treatment were analysed using the paired $t$ test (two tailed). The post-EPBD and post-EST groups were compared using the Mann-Whitney U test or two tailed Fisher's exact test, which considered baseline characteristics, manometric data, incidence of pneumobilia, and incidence of ensuing complications. A p value $<0.05$ was considered significant.

Retrospectively, 200 post-EPBD and 91 post-EST patients were additionally recruited for a detailed analysis of the cumulative 
Table 3 Incidence (number (\%)) of pneumobilia and other complications one year after EPBD or EST

\begin{tabular}{lll}
\hline & $\begin{array}{l}\text { Post-EPBD } \\
(n=35)\end{array}$ & $\begin{array}{l}\text { Post-EST } \\
(n=35)\end{array}$ \\
\hline Pneumobilia & $3(8.6)^{\star \star}$ & $14(40)^{\star \star}$ \\
Recurrent CBD stones & $2(5.7)$ & $3(8.67)$ \\
Cholecystitis & $1 / 30(3.37)$ & $1 / 26(3.8)$ \\
\hline
\end{tabular}

EPBD, endoscopic papillary balloon dilation; CBD, common bile duct; EST, endoscopic sphincterotomy. ${ }^{\star \star} \mathrm{p}<0.01$.

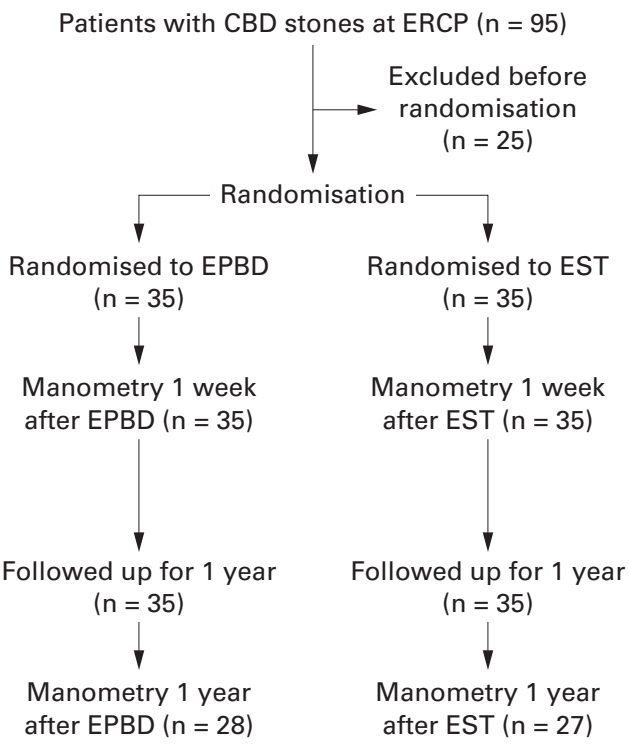

Figure 1 Trial profile. EPBD, endoscopic papillary balloon dilation; $C B D$, common bile duct; EST, endoscopic sphincterotomy; ERCP, endoscopic retrograde

cholangiopancreatography.

incidence of later complications. These patients received EPBD or EST between June 1995 and January 2000, except for the period of the randomised trial (January 1998-January 1999). Their follow up care consisted of a visit every six months. If the patient did not visit the hospital, he or she was contacted by telephone and interviewed about ensuing complications. Thus the study included a total of 235 (200 retrospective and 35 randomised) patients in the EPBD group and 126 (91 retrospective and 35 randomised) in the EST group. The cumulative incidence of ensuing complications was analysed by the Kaplan-Meier method. The difference between curves was examined statistically using the log rank test.

\section{Results}

PATIENT BASELINE CHARACTERISTICS AND EARLY COMPLICATIONS

Ninety five patients were diagnosed as having CBD stones by ERCP at our institutions between January 1998 and January 1999. Thirteen were excluded: severe acute cholangitis with pancreatitis by impacted stone in two patients, biliary cancer in two patients, coagulopathy due to severe liver cirrhosis in one patient, and a history of prior EST in eight patients. Written informed consent was obtained from the remaining 82 patients. Selective deep cannulation to the CBD and subsequent endoscopic manometry was successful in 70 patients without the use of antispastic drugs or precut of the papilla. After endoscopic manometry, patients were randomly assigned to EPBD or EST using blinded sealed envelopes. Each group consisted of 35 patients. The demographic characteristics used for randomisation were age, sex, number of stones, diameter of the largest stone, and diameter of the CBD. No significant difference was found between the EPBD and EST groups with regard to patient characteristics at baseline (table 1). Complete stone clearance was achieved in all patients. Mechanical lithotripsy was used more frequently in EPBD than in EST (significant difference) (table 1). Early complications occurred in five patients. Two patients in each group had mild pancreatitis after treatment but symptoms resolved in a few days with conservative treatment. Mild bleeding was also observed in one patient during EST but it stopped spontaneously. Severe complications such as severe pancreatitis, duodenal perforation, or massive bleeding did not occur in any of the cases studied. The gall bladder was preserved in 30 of the post-EPBD patients and in 26 post-EST patients. Gall bladder stones were present in 23 post-EPBD and 21 post-EST patients (table 1 ).

\section{MANOMETRIC ANALYSIS AND LATER}

\section{COMPLICATIONS}

CBD pressure, SO basal and peak pressures, and SO contraction frequency in the EPBD and EST groups at entry were within the following ranges: CBD pressure, $4.6(0.3) \mathrm{mm}$ $\mathrm{Hg}$; SO basal pressure, $9.0(0.9) \mathrm{mm} \mathrm{Hg}$; SO peak pressure, $111.0(3.8) \mathrm{mm} \mathrm{Hg}$; and $\mathrm{SO}$ contraction frequency, $8.5(0.4)$ per minute. There may have been an effect of the presence of stones on baseline manometric findings although the data were distributed in the normal range.

Endoscopic manometry data one week after treatment are shown in table 2. All parameters of SO function of post-EST patients were significantly lower than those of post-EPBD patients. In 23 of the 35 post-EST patients, contraction waves had disappeared completely.

At one year after EPBD or EST, the incidence of pneumobilia was significantly higher in post-EST than in post-EPBD patients $(\mathrm{p}<0.01)$ (table 3$)$. In both groups, posttreatment complications included recurrent $\mathrm{CBD}$ stones and cholecystitis. However, the incidence of such later complications was not significantly different between the two groups (table 3). All patients with recurrent CBD stones were treated successfully by endoscopic procedures, and two patients had cholecystitis which resolved with conservative treatment such as fasting and antibiotics.

Five patients suffered recurrent CBD stones and underwent additional endoscopic treatment during the one year follow up. Ten patients withdrew consent and rejected manometry one year after treatment. Thus series manometric analysis was completed in 55 patients: 28 from the EPBD group and 27 from the EST group (fig 1). One week after EPBD, CBD pressure, SO basal pressure, SO peak 

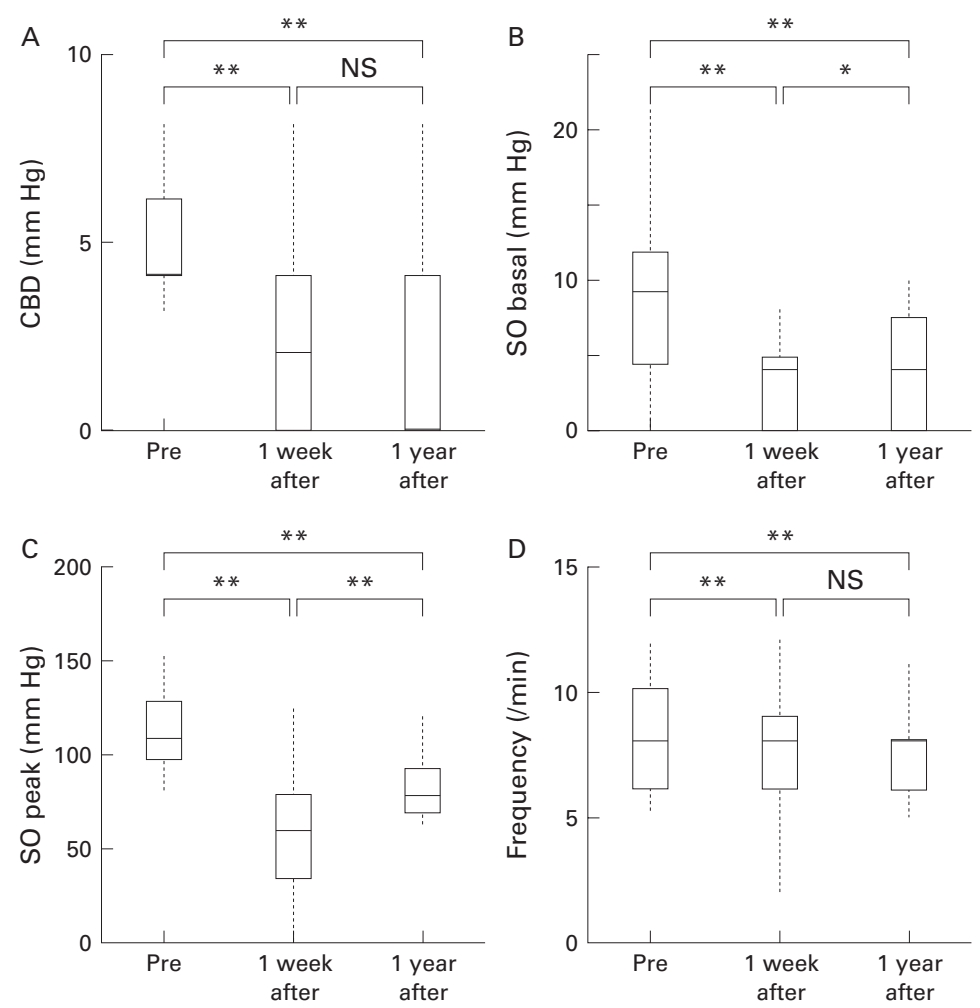

Figure 2 Common bile duct (CBD) pressure (A), sphincter of Oddi (SO) basal and peak pressures $(B, C)$, and $S O$ contraction frequency (D) before (Pre), one week after, and one year after endoscopic papillary balloon dilation (EPBD) in patients with CBD stones. Data are expressed by the outlier box plot generated by $\mathcal{F M P} v .4$ software. The box represents the 25th and 75th quantiles (quartiles), with the line in the middle of the box identifying the median; the broken lines indicate the upper quartile $+1.5 \times$ (interquartile range) and the lower quartile $-1.5 \times$ (interquartile range), respectively. ${ }^{\star} p<0.05$, $\star \star p<0.01$.

Table 4 Comparison of post-EPBD and post-EST manometric data one year after treatment

\begin{tabular}{lcc}
\hline & Post-EPBD $(n=28)$ & Post-EST $(n=27)$ \\
\hline CBD pressure $(\mathrm{mm} \mathrm{Hg})$ & $2.1(0.5)^{\star \star}$ & $0.7(0.3)^{\star \star}$ \\
SO basal pressure (mm Hg) & $4.2(0.6)^{\star \star}$ & $1.6(0.6)^{\star \star}$ \\
SO peak pressure (mm Hg) & $74.6(6.1)^{\star \star}$ & $16.9(4.9)^{\star \star}$ \\
SO contraction frequency (per min) & $7.2(0.5)^{\star \star}$ & $2.7(0.8)^{\star \star}$ \\
\hline
\end{tabular}

EPBD, endoscopic papillary balloon dilation; CBD, common bile duct; EST, endoscopic sphincterotomy; SO, sphincter of Oddi

Values are mean $(\mathrm{SEM})$.

${ }^{\star \star} \mathrm{p}<0.01$.

Table 5 Baseline characteristics of post-EPBD and post-EST patients

\begin{tabular}{|c|c|c|}
\hline & Post-EPBD $(n=235)$ & Post-EST $(n=126)$ \\
\hline Age $(y)^{a}$ & $68.6(28-95)$ & $69.3(29-90)$ \\
\hline $\operatorname{Sex}(\mathrm{F} / \mathrm{M})$ & $105 / 130$ & $55 / 71$ \\
\hline No of stones ${ }^{a}$ & $3.3(1-20)$ & $3.5(1-20)$ \\
\hline Diameter of largest stone $(\mathrm{mm})^{\mathrm{a}}$ & $12.7(4-47)$ & $13.6(5-42)$ \\
\hline Diameter of CBD $(\mathrm{mm})^{\mathrm{a}}$ & $14.7(6-32)$ & $16.1(8-42)$ \\
\hline Use of mechanical lithotripsy ${ }^{\mathrm{b}}$ & $35(15)$ & $16(13)$ \\
\hline Use of ESWL & $46(20)$ & $20(16)$ \\
\hline Call bladder in situ ${ }^{\mathrm{b}}$ & $150(64)$ & $68(54)$ \\
\hline Concomitant gall bladder stone $\mathrm{e}^{\mathrm{b}}$ & $110 / 150(73)$ & $48 / 68(71)$ \\
\hline Duration of follow up (months) ${ }^{a}$ & $36.3(12-67)$ & $37.4(12-67)$ \\
\hline
\end{tabular}

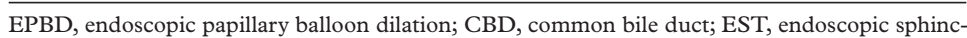
terotomy.

${ }^{a}$ Values are mean (range).

balues are incidence rates (number $(\%)$ ).

pressure, and SO contraction frequency decreased significantly compared with pre-EPBD values (fig $2 \mathrm{~A}-\mathrm{D})$ ). SO basal and peak pressures at one year recovered significantly compared with pressures measured one week after EPBD; however, these values remained significantly low compared with pre-EPBD levels (fig $2 \mathrm{~B}$,
C). Overall, values of all parameters one year after EPBD were significantly lower than pre-EPBD values (fig $2 \mathrm{~A}-\mathrm{D}$ ). In post-EST patients, recovery of $\mathrm{SO}$ function was not observed and contraction waves had disappeared and remained completely undetected in 17 of the 27 post-EST patients. Consequently, all parameters of SO function of post-EST patients remained significantly lower than those of post-EPBD patients at one year after treatment (table 4).

INCIDENCE OF PNEUMOBILIA AND LATER COMPLICATIONS IN THE RETROSPECTIVE STUDY No significant difference was found in baseline characteristics between the two groups (table 5). The median follow up periods were 36.3 months (range 12-67) and 37.4 months (range 12-67) in the post-EPBD and post-EST groups, respectively. Pneumobilia appeared at a significantly higher rate in post-EST patients $(50 / 126,40 \%)$ than in post-EPBD patients $(21 / 235,8.9 \%)(p<0.01)$. The incidence of later complications such as recurrent CBD stones, cholangitis, and cholecystitis, as well as pneumobilia, is shown in table 6 . The gall bladder was preserved in situ in 150 of the post-EPBD patients and in 68 of the post-EST patients. Among those, accompanying gall bladder stones were present in 110 post-EPBD patients and in 48 post-EST patients. The recurrence rate of CBD stones was not significantly different between the two groups. Cholangitis without stone recurrence was observed only in the post-EST group. Cholecystitis was observed significantly more often in the post-EST group than in the post-EPBD group $(p<0.05)$; however, the incidence was not significantly different between patients with and without gall bladder stones in either group.

The cumulative incidence of ensuing complications was analysed by the Kaplan-Meier method. Cholangitis without stone recurrence could not be clinically distinguished from that with stone recurrence because the recurrent stone might have fallen from the CBD at ERCP. Therefore, these categories were combined as biliary complications. As a result, a significant difference was found between the two groups with regard to the incidence of complications such as biliary complications and cholecystitis $(\mathrm{p}<0.05$ by the log rank test) (fig 3A, B).

\section{Discussion}

EST is now a standard procedure for the removal of CBD stones. It is considered comparatively safe, convenient, inexpensive, and effective. However, it should be noted that there are several drawbacks to EST. Acute complications can occur, such as bleeding, duodenal perforation, and pancreatitis. In addition, EST causes the permanent loss of sphincter function. Moreover, pneumobilia and reflux are observed in approximately 50\% of EST patients and almost $100 \%$ of patients will develop either symptomatic or asymptomatic bacteriocholia. ${ }^{12}$ Subsequent duodenobiliary reflux and bacterial contamination can 
Table 6 Incidence (number (\%)) of pneumobilia and later complications after EPBD or EST

\begin{tabular}{|c|c|c|c|c|c|c|}
\hline & \multicolumn{3}{|c|}{ Post-EPBD $(n=235)$} & \multicolumn{3}{|c|}{ Post-EST $(n=126)$} \\
\hline & $\begin{array}{l}\text { Total } \\
(n=235)\end{array}$ & $\begin{array}{l}\text { GB in situ } \\
(n=150)\end{array}$ & $\begin{array}{l}\text { With GB } \\
\text { stone } \\
(n=110)\end{array}$ & $\begin{array}{l}\text { Total } \\
(n=126)\end{array}$ & $\begin{array}{l}\text { GB in situ } \\
(n=68)\end{array}$ & $\begin{array}{l}\text { With GB } \\
\text { stone } \\
(n-48)\end{array}$ \\
\hline Pneumobilia & $21(8.9)^{\star \star}$ & - & - & $50(40)^{\star \star}$ & - & - \\
\hline Recurrent CBD stones & $23(10)$ & $14(9.3)$ & $10(9.1)$ & $18(14)$ & $7(10)$ & $5(10)$ \\
\hline Cholangitis & 0 & 0 & 0 & $4(3.2)$ & $3(4.4)$ & $2(4.2)$ \\
\hline Cholecystitis & - & $3(2.0)$ & $3(2.7)$ & - & $6(8.8)$ & $5(10)$ \\
\hline
\end{tabular}

EPBD, endoscopic papillary balloon dilation; CBD, common bile duct; EST, endoscopic sphincterotomy; GB, gall bladder. ${ }^{\star \star} \mathrm{p}<0.01$.

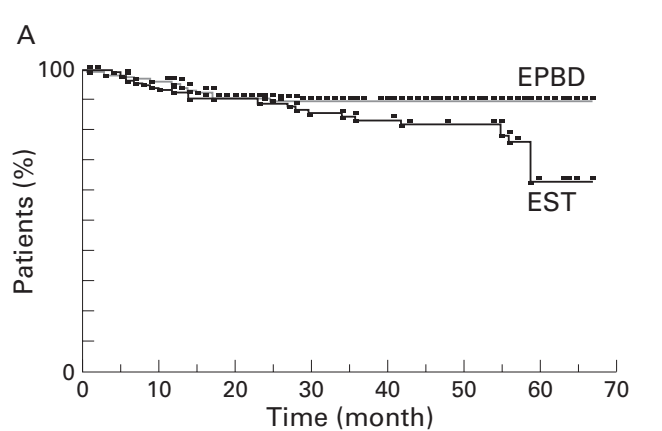

B

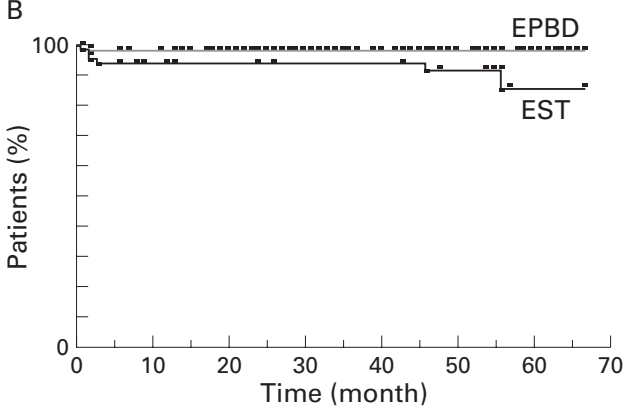

Figure 3 Kaplan-Meier estimates of the proportion of patients without biliary complications $(A)$ in the post-endoscopic papillary balloon dilation (EPBD) $(n=235)$ and post-endoscopic sphincterotomy (EST) patients $(n=126)(p<0.05)$ or cholecystitis $(B)$ in the post-EPBD $(n=150)$ and post-EST patients $(n=68)$ $(p<0.05)$.

cause symptomatic complications such as acute cholecystitis and cholangitis, ${ }^{13}$ and further problems can be induced due to chronic inflammation of the biliary system. EST is associated with bacterial colonisation, the presence of cytotoxic components in bile, and chronic inflammation with fibrosis and reactive epithelial changes of the biliary system. ${ }^{14}$ Some reports have indicated that papillary destruction may lead to malignant transformation of the choledochal epithelium ${ }^{15}$ and increase the incidence of biliary tract cancer. ${ }^{16}$ Therefore, other procedures that can preserve the physiological function of the biliary tract may be advantageous, especially in younger patients.

Compared with EST, EPBD causes little trauma to the papilla and does not extend the orifice to a greater degree. Because of this benefit, the procedure is considered to preserve papillary function; however, only a few reports have actually demonstrated such preservation. Minami and colleagues ${ }^{10}$ evaluated papillary function before and one month after EPBD by endoscopic manometry, and reported complete preservation of SO function. Sato and colleagues ${ }^{11}$ reported that SO function was significantly reduced one week after EPBD but that it recovered one month later. Overall, no significant difference was reported between $\mathrm{SO}$ function measured before and one month after EPBD. Moreover, in a histopathological analysis of a porcine model, MacMathuna and colleagues $^{17}$ demonstrated post-EPBD preservation of papillary smooth muscle integrity. They concluded that EPBD caused an acute transmural inflammatory response and chronic follicular hyperplasia but that it did not alter the papillary architecture.

Nevertheless, we have often observed that the orifice of the papilla becomes somewhat loose, facilitating cannulation into the CBD; this can occur even later than one year following EPBD. In our manometric study, all parameters (CBD pressure, SO basal pressure, SO peak pressure, and SO contraction frequency) decreased significantly one week after EPBD compared with pre-EPBD values. After one year, SO basal and peak pressures recovered significantly compared with those measured one week after EPBD but they still remained significantly low compared with preEPBD levels. Overall, the values of all parameters one year after EPBD were significantly lower than those of the pre-EPBD values. This manometric finding agrees with clinical experience. Pneumobilia appeared in some cases following EPBD although its incidence was extremely low compared with that after EST. These data suggest that papillary function is not necessarily preserved following EPBD.

It should be noted that our results differ from those of previous reports. ${ }^{11117}$ Balloon diameter, inflation pressure, and duration of inflation were relatively similar among reports. However, the experimental study by MacMathuna and colleagues ${ }^{17}$ involved balloon inflation of the papilla but not stone extraction. Furthermore, other manometric studies have not described in detail the diameter and number of stones. These differences may explain the observed discrepancy. It is generally considered that balloon inflation of $8 \mathrm{~mm}$ in diameter allows extraction of stones smaller than $10 \mathrm{~mm}$ in diameter. In our experience, it is not always so straightforward. Sometimes it is necessary to force larger stones through the papilla. Simultaneous extraction of a number of stones may also be difficult. Thus not only balloon inflation but also the process of stone extraction may injure the papilla. To prevent such injury, a mechanical lithotriptor may be 
useful. On the other hand, the use of a lithotriptor renders the procedure more complicated and incurs a higher incidence of pancreatitis. $^{18}$

Hence the degree of papillary damage varies from case to case. Although papillary function is completely preserved in some cases, it may also be almost completely destroyed. Furthermore, pneumobilia can occur in some cases. We tried to analyse the injury factor in our manometric study by stratifying patients based on stone size. However, a significant difference was not found due to the small number of subjects. In fact, in the three cases that presented pneumobilia after EPBD, the diameter of the largest stone was $15 \mathrm{~mm}, 10 \mathrm{~mm}$, and $17 \mathrm{~mm}$, and the number of stones was 16, 12, and 3, respectively; thus all cases had large stones or many stones.

The clinical implications of the degree of papillary damage or preservation remain unclear. In most patients treated with EPBD in the current study, papillary function was at least partially preserved. If there remains any degree of papillary function, there may be no clinical problem. Bergman and colleagues ${ }^{5}$ observed a reduced rate of cholecystitis after EPBD compared with EST and hypothesised that sphincter preservation may explain this. Ochi and colleagues ${ }^{8}$ also reported similar results. In our controlled studies, there was no significant difference in the incidence of cholecystitis between the two groups. In addition, the recurrence rate of CBD stones was similar between the post-EPBD and post-EST groups. However, patient numbers in this study were small and duration of follow up was short. The incidence of later complications was extremely low, and the power of the study to exclude a significant difference between the two groups may have been insufficient. On the other hand, a significant difference was observed in the incidence of biliary complications and cholecystitis in our larger retrospective study which had a longer follow up period. This result may indicate that preservation of $\mathrm{SO}$ function prevents the later complications, and is clinically beneficial, even though follow up in this study was not as strict as that in the prospective study.

The main limitation of our study was the mixed prospective/retrospective analysis of late complications. Their occurrence was somewhat lower in the retrospective group. But most cases with complications had some symptoms, not only in the retrospective group but also in the prospective study. Therefore, we believe the actual incidence of symptomatic complications may be similar in each group.
In conclusion, EPBD cannot always completely preserve sphincter of Oddi function. In most cases, EPBD renders SO function somewhat reduced. However, SO function can be preserved to a greater degree than with EST. Additional, prospective, large, long term follow up data are necessary to examine the contribution of EPBD to ensuing complications, and to determine the clinical significance of papillary damage.

1 Staritz M, Ewe K, Meyer zum Buschenfelde KH. Endoscopic papillary dilation (EPD) for the treatment of common bile duct stones and papillary stenosis. Endoscopy 1983;15:197-8

2 May GR, Cotton PB, Edmunds SE, et al. Removal of stones from the bile duct at ERCP without sphincterotomy. Gastrointest Endosc 1993;39:749-54.

3 MacMathuna P, White P, Clarke E, et al. Endoscopic sphincteroplasty: a novel and safe alternative to papillotomy in the management of bile duct stones. Gut 1994;35:127-9.

4 MacMathuna P, White P, Clarke E, et al. Endoscopic balloon sphincteroplasty (papillary dilation) for bile duct stones; efficacy, safety, and follow-up in 100 patients. Gastrointest Endosc 1995; 42:468-74.

5 Bergman JJGHM, Rauws EAJ, Fockens P, et al. Randomized trial of endoscopic balloon dilation versus endoscopic phincterotomy for removal of bile duct stones. Lancet 1997;349:1124-9.

6 Kawabe T, Komatsu Y, Tada M, et al. Endoscopic papillary balloon dilation in cirrhotic patients: removal of common bile duct stones without sphincterotomy. Endoscopy 1996; 28:694-8

7 Komatsu Y, Kawabe T, Toda N, et al. Endoscopic papillary balloon dilation for the management of common bile duct stones: experience of 226 cases. Endoscopy 1998;30:12-17.

stones: experience of 226 cases. Endoscopy $1998 ; 30: 12-17$.
8 Ochi Y, Mukawa K, Kiyosawa K, et al. Comparing the treatment outcomes of endoscopic papillary dilation and endoscopic sphincterotomy for removal of bile duct stones. $\mathcal{F}$ Gastroenterol Hepatol 1999;14:90-6.

9 Ueno N, Ozawa Y. Endoscopic sphincter dilation in patients with bile duct stones: immediate and medium-term results. f Gastroenterol Hepatol 1999;14:822-6.

10 Minami A, Nakatsu T, Uchida N, et al. Papillary dilation vs sphincterotomy in endoscopic removal of bile duct stones-a randomized trial with manometric function. Dig Dis Sci 1995;40:2550-4.

11 Sato H, Kodama T, Takaaki J, et al. Endoscopic papillary balloon dilatation may preserve sphincter of Oddi function after common bile duct stone management: evaluation from the viewpoint of endoscopic manometry. Gut 1997;41:541-4.

12 Seifert E. Long-term follow-up after endoscopic sphincterotomy (EST). Endoscopy 1988;20:232-5.

13 Ikeda S, Tanaka M, Matsumoto S, et al. Endoscopic sphincterotomy: long-term results in 408 patients with complete follow-up. Endoscopy 1988;20:13-17.

14 Bergman JJGHM, van Berkel AM, Groen AK, et al. Biliary manometry, bacterial characteristics, bile composition, and histologic changes fifteen to seventeen years after endoscopic sphincterotomy. Gastrointest Endosc 1997;45:400-5.

Scopic sphincterotomy. Gastrointest Endosc 1997;45:400-5.
15 Kurumado K, Nagai T, Kondo Y, et al. Long-term observations on morphological changes of choledochal epithelium after choledochoenterostomy in rats. Dig Dis Sci 1994;39: 809-20.

16 Hakamada K, Sasaki M, Endoh M, et al. Late development of bile duct cancer after sphincteroplasty: A ten- to twentytwo- year follow-up study. Surgery 1997;121:488-92.

17 MacMathuna P, Siegenberg D, Gibbons D, et al. The acute and long-term effect of balloon sphincteroplasty on papillary structure in pigs. Gastrointest Endosc 1996;44: 650-5.

18 Yasuda I, Tomita E, Moriwaki $\mathrm{H}$, et al. Endoscopic papillary balloon dilatation for common bile duct stones: efficacy of combination with extracorporeal shockwave lithotripsy for large stones. Eur f Gastroenterol Hepatol 1998;10:1045-50. 